\title{
Medial Collateral Ligament Reconstruction in Multi- Ligament Knee Injury: Introducing a Simple Technique
}

\author{
Abolfazl Bagherifar, Mahmood Jabalameli, Hosseinali Hadi, Salman Ghafari, Ali Shahsavari Poor* and \\ Mehrdad Bahrabadi
}

Bone and Joint Reconstruction Research Center, Iran University of Medical Sciences, Iran

Submission: October 27, 2017; Published: November 13, 2017

*Corresponding author: Ali Shahsavaripour, Shafa Orthopedic Hospital, Mojahedin Islam Avenue, Shohada Sq, Tehran, Iran, Tel: +98(21)33542000-8; Fax: +98(21)33542020; Email: Ali.shahsavari2@gmail.com

Abstract

Background: Surgical reconstruction of medial collateral ligament, (MCL), of the knee joint can be performed by different methods, each with some advantages, and some disadvantages. Due to the good results of conservative treatment of MCL injury, and the high complication rate of complex reconstructions, the need for a simpler method of reconstruction felt.

Objectives: The aim of this study was to assess the results of MCL reconstruction in multiligament knee injuries by a simple and fast method.

Patients and Methods: Nineteen patients with multiligament knee injuries, with the average age of 35.73 (Range 22 to 50 ) were treated by Ligament reconstruction, and included in our study. All patients treated by a simple method of transferring a semitendinosus around the adductor magnus tendon. In the last follow-up visit, physical examination including a valgus stress test, was performed for all patients, and International Knee Documentation Committee (Subjective, and Objective), and Tegner Lysholm questioners were filled for them.

Results: The average follow-up time was 21.36 months. The pattern of ligament injury was seven MCL and anterior cruciate ligament, (ACL), two MCL and posterior cruciate ligament,(PCL), eight MCL+ACL+PCL, and two patients with MCL+ACL+PCL+ lateral collateral ligament, (LCL). The group of patients with ACL plus MCL injuries had better results than other groups. No patient had more than ten millimeters of valgus stress test. One patient had knee stiffness, and another one had hypoesthesia of leg.

Conclusion: This technique is a simple yet effective method of MCL reconstruction which can be easily learned. The time of surgery is short, and the incision needed is small. It has lower rate of knee stiffness, with good functional results.

Keywords: Medial collateral ligament; Multiligament knee injury; Reconstruction

Abbreviations: ACL: Anterior Cruciate Ligament; PCL: Posterior Cruciate Ligament; LCL: Lateral Collateral Ligament; MCL : Medial Collateral Ligament

\section{Introduction}

MCL tear is the most common ligament injury of the knee [1]. Most isolated injuries are treated conservatively. Combined ligament injuries of the knee may need more than conservative care. This combination might be quite often up to $78 \%$ in one series of grade III MCL injuries [2]. One of the most common reasons for surgery in MCL injury is association of cruciate ligament tear [3]. Conservative treatment of MCL tear in multiligament injuries had a good outcome in different studies [4-8].

MCL reconstruction is necessary for the treatment of chronic instability, or prevention of valgus overload on the reconstructed cruciate ligaments, if MCL fails to heal after conservative treatment [9-10]. There are different techniques of MCL reconstruction including semitendinosus autograft with tibial attachment preservation [11-14], allograft [15,16], or double bundle reconstruction $[13,15-18]$. The reconstruction technique which is performed in this study is a kind of tendon transfer, which is a simple method. The objective of this study is to assess the functional result of this method of MCL reconstruction.

\section{Methods}

Inclusion criteria were all patients with multiligament knee injuries who were treated surgically with at least MCL reconstruction. Exclusion criteria were:

i. MCL reconstruction with other surgical techniques 
ii. Patients who lost to follow-up and

iii. Patients with associated fracture around the knee.

\section{Surgical Technique}

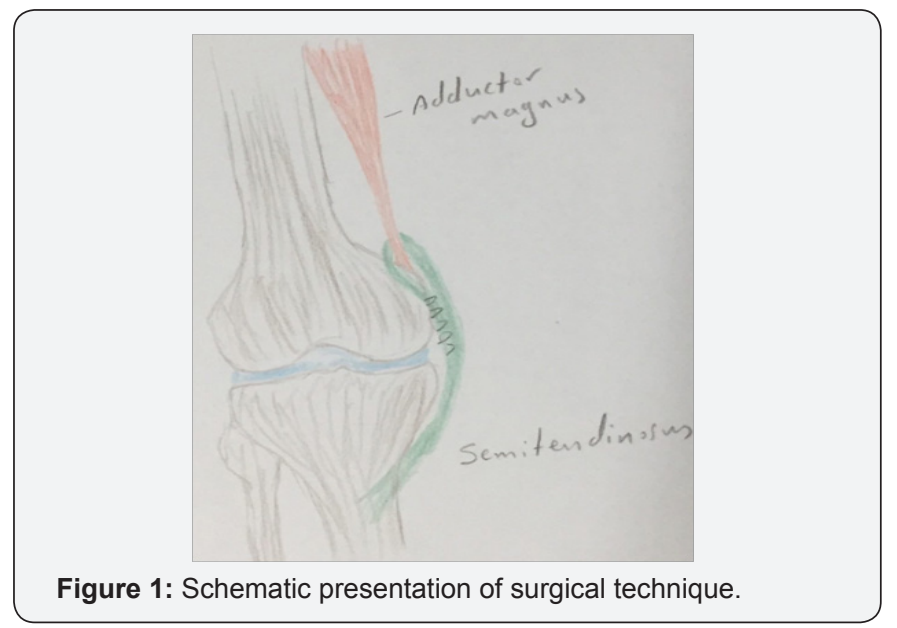

A four centimeter incision posterior to adductor tubercle, running two centimeters above and below it was performed. After incising deep fascia, the first tendon to be seen is semitendinosus. Distal insertion of semitendinosus is remained intact, but proximal part of the tendon is detached from muscle tendon insertion. At the proximal extent of the incision, just above the adductor tubercle, tendon of adductor magnus is identified. Free end of the semitendinosus tendon is passed around adductor Magnus tendon, from posterior to anterior direction and re attached on itself with non-absorbable sutures in full knee extension (Figure 1) the tension of the graft was around 10 newtons at the time of fixation.

Postoperatively, patients were on a partial weight bearing with a hinged knee brace protocol for 6 to 8 weeks. Range of motion was started with a hinged knee brace in place two weeks after surgery, under supervision of a physiotherapist, and gradually increased to full range, 8-12 weeks after the operation. Hinged knee brace was discontinued after three months from the time of surgery. The amount of medial gap, was assessed based on the opening of medial joint space, and was graded as zero (0$2 \mathrm{~mm})$, one plus (2-5 $\mathrm{mm})$, two plus (6-10 $\mathrm{mm})$, and three plus (more than $10 \mathrm{~mm}$ ).

The method of surgery, in all patients included arthroscopic ACL, and PCL reconstruction, and open reconstruction of collaterals. In the last follow-up visit, patients were assessed for any complication after surgery, and subjective and objective IKDC, and Tegner Lysholm questioner were filled. Valgus stress test in full extension, and $30^{\circ}$ flexion were performed. The results are evaluated by the SPSS version 22 . Written consent was obtained from all patients to publish the results of their treatment, and the study was approved by ethical committee of our center.

\section{Results}

Table 1: Demographic, clinical characteristics and outcome in 19 cases of multiligament knee reconstruction. A: Anterior Cruciate Ligament; P: Posterior Cruciate Ligament; M: Medial Collateral Ligament; L: Lateral Collateral Ligament.

\begin{tabular}{|c|c|c|c|c|c|c|c|c|c|}
\hline Number & Age & Gender & Ligament & Follow up & IKDC sub & IKDC objective & Valgus test(plus) & Complication & TL score \\
\hline 1 & 50 & M & $\mathrm{A}+\mathrm{P}+\mathrm{M}$ & 16 & 47.1 & C & 2 & No & 67 \\
\hline 2 & 29 & M & $A+M$ & 33 & 89.7 & $\mathrm{C}$ & 2 & No & 97 \\
\hline 3 & 37 & M & $\mathrm{A}+\mathrm{M}$ & 30 & 52.9 & C & 0 & No & 84 \\
\hline 4 & 39 & M & $\mathrm{A}+\mathrm{P}+\mathrm{M}+\mathrm{L}$ & 29 & 78.2 & D & 0 & $\begin{array}{c}\text { Stiffness: } \\
\text { manipulation }\end{array}$ & 90 \\
\hline 5 & 31 & M & $\mathrm{P}+\mathrm{M}$ & 9 & 67.8 & $\mathrm{C}$ & 1 & No & 77 \\
\hline 6 & 32 & M & $A+M$ & 16 & 60.9 & $\mathrm{C}$ & 2 & No & 87 \\
\hline 7 & 26 & M & $A+M$ & 36 & 98.2 & B & 1 & No & 100 \\
\hline 8 & 39 & $\mathrm{~F}$ & $\mathrm{~A}+\mathrm{P}+\mathrm{M}$ & 12 & 54 & D & 2 & No & 80 \\
\hline 9 & 25 & M & $\mathrm{A}+\mathrm{P}+\mathrm{M}$ & 18 & 69 & $\mathrm{C}$ & 2 & No & 80 \\
\hline 10 & 30 & M & $\mathrm{A}+\mathrm{M}$ & 31 & 89.7 & B & 1 & No & 94 \\
\hline 11 & 30 & M & $\mathrm{A}+\mathrm{P}+\mathrm{M}$ & 28 & 65.5 & C & 1 & No & 84 \\
\hline 12 & 44 & M & $\mathrm{A}+\mathrm{P}+\mathrm{M}$ & 11 & 41.4 & D & 1 & No & 56 \\
\hline
\end{tabular}




\section{Orthopedics and Rheumatology Open Access Journal}

\begin{tabular}{|c|c|c|c|c|c|c|c|c|c|}
\hline 13 & 50 & $\mathrm{M}$ & $\mathrm{A}+\mathrm{P}+\mathrm{M}+\mathrm{L}$ & 14 & 42.5 & $\mathrm{C}$ & 0 & No \\
\hline 14 & 44 & $\mathrm{M}$ & $\mathrm{P}+\mathrm{M}$ & 30 & 36.8 & $\mathrm{C}$ & 0 & Hypoesthesia & \multicolumn{2}{c|}{ No } \\
\hline 15 & 35 & $\mathrm{M}$ & $\mathrm{A}+\mathrm{P}+\mathrm{M}$ & 10 & 62 & $\mathrm{D}$ & 2 & No \\
\hline 16 & 22 & $\mathrm{M}$ & $\mathrm{A}+\mathrm{M}$ & 12 & 25.3 & $\mathrm{C}$ & 1 & No \\
\hline 17 & 24 & $\mathrm{M}$ & $\mathrm{A}+\mathrm{M}$ & 7 & 72.4 & $\mathrm{~B}$ & 0 & 95 \\
\hline 18 & 43 & $\mathrm{~F}$ & $\mathrm{~A}+\mathrm{P}+\mathrm{M}$ & 37 & 41.4 & $\mathrm{C}$ & 2 & No \\
\hline 19 & 49 & $\mathrm{M}$ & $\mathrm{A}+\mathrm{P}+\mathrm{M}$ & 27 & 89.7 & $\mathrm{~B}$ & 0 & 95 \\
\hline
\end{tabular}

Twenty-one patients with multiligament knee injuries were surgically treated. Two patients were lost to follow-up, remaining nineteen patients including two women, and seventeen men with, with the average age of 35.73 years \pm 9.06 (22 to 50 years) for the last follow-up. The average follow-up time was 21 months (range 7 to 37 months). The pattern of ligament injury was: seven patients with MCL + ACL injuries; two patients with MCL + PCL; eight patients with MCL+ACL+PCL; and two patients with $\mathrm{MCL}+\mathrm{ACL}+\mathrm{PCL}+\mathrm{LCL}$ injuries. All patients treated by a simple method of transferring a semitendinosus around the adductor magnus tendon. (Table 1).

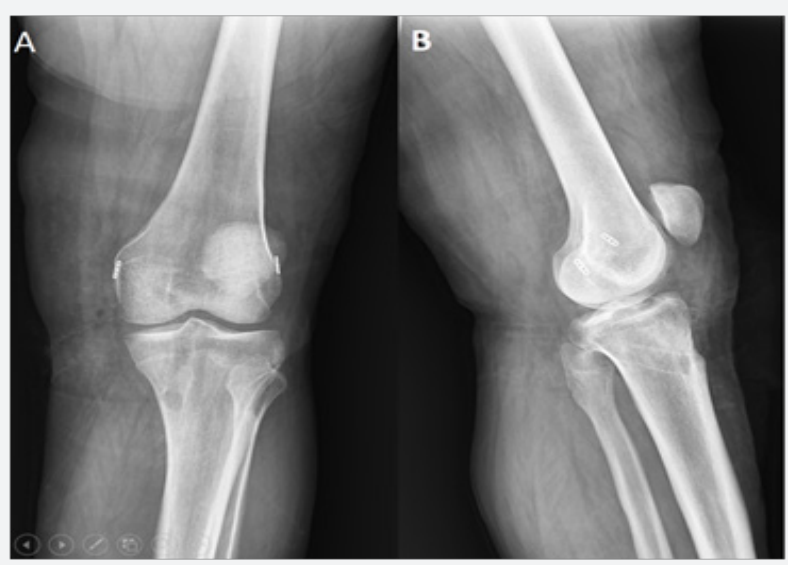

Figure 2: Post-operative anteroposterior, and lateral radiographies of a patient with $A C L+P C L+M C L$ reconstruction.

The range of IKDC score was between 25.3 to $98.2 \pm 10.1$ (mean 62.34). The mean Tegner Lysholm score was $80.36 \pm 15.44$ (range 48 to 100). The group of patients with ACL plus MCL injuries had better results than other groups, but the difference was not statistically significant $(\mathrm{P}=0.332$ ) (Figure 2$)$. The results of IKDC, and Tegner Lysholmscores were better in younger patients than older individuals, but there was not statistically significant $(\mathrm{P}=0.184)$. Valgus stress test in extension was less than two millimeters in six patients, two to five millimeters in six patients, between six and ten millimeters in seven patients, and no patient had more than ten millimeters of valgus stress test. This test was repeated in $30^{\circ}$ flexion, and the results were one plus higher. Complications were seen in two patients. One patient suffered from post-operative hypoesthesia at medial leg which might be due to the injury to the saphenous nerve during surgery, and the other one had knee stiffness which relieved by manipulation under general anesthesia.

\section{Discussion}

\section{Conservative Treatment}

Conservative methods of treatment in grade III MCL injuries have had good results even in professional athletes in some report [4]. In another study, with 18 patients having ACL, and MCL injuries, MCL tears have been treated conservatively after early surgical reconstruction of ACL tear, and authors described good results with this treatment strategy [6]. Shelbourne et al. [5] reported on 68 patients with combined ACL and MCL tears who were treated by late ACL reconstruction and conservative MCL treatment. All patients reported satisfactory outcome and 95\% of patients returned to pre-injury activities. In a RCT study, 47 patients with primary ACL reconstruction, half of patients were treated by surgical method, and another half by conservative treatment. There was no difference in functional stability, ROM, strength, and return to activity, and medial gap during valgus stress test was not statistically different from uninjured side [8]. Results of these studies show that even conservative methods of treatment can return MCL to good function. Based on these results, we assumed that for the reconstruction of MCL, patients do not need more than a simple method.

\section{Surgical Treatment}

Results of our study shows a good medial side knee stability, demonstrated by zero to one plus valgus instability. Seven patients had two plus valgus instability, and no patient had more than this instability. We had only one knee stiffness which was relieved by knee manipulation under anesthesia. Surgical treatment of medial structures of the knee is very invasive, with some potential complications. The most common complication of MCL reconstruction is knee stiffness [19]. The stiffness may 
be more severe with anterior mobilization of posteromedial capsule [18]. In using allograft tissue for reconstruction, there are other draw backs such as infection, extra cost, and lack of tissue availability [20]. Autograft harvest has also its own tradeoffs, including donor site morbidity, potential weakness of dynamic medial stabilizers, and questionable quality of autograft after the patient experiences trauma [21].

Anatomic reconstruction of the MCL by a double bundle technique, can restore original proximal and distal MCL attachment anatomy, and lead to individual tensioning of superficial MCL, and POL [22,23]. These methods obviously have better results, but at the same time two major complications:

a. They are more demanding techniques needing more extensive exposures, more tunnels through bone; and more hardware. Some of these procedures with a large medial incision results a restricted knee motion in $20 \%$ of patients [14].

b. Distal attachment of the graft on tibia is not strong enough. In addition, double bundle construct may be significantly stronger and stiffer than a native MCL, which theoretically can lead to altered knee biomechanics [24].

We used a tendon transfer technique in which semitendinosus tendon can satisfy the need for allograft tissue, and an additional bone tunnel and fixation side for the superficial MCL on the tibia. Due to the small size of the incision used in our technique resulting in a less aggressive surgery, and suturing the tendon in full knee extension, we did not have any restricted knee ROM Our technique is simple, and fast, and can be learned easily. Due to the time consuming procedures of ACL, or PCL reconstruction in multiligament injuries, our technique which can be performed very fast, relieves the need for long standing tourniquet time, a main concern in knee ligament reconstruction.

However, maintenance of the existing distal semitendinosus insertion results in an excessively anterior tibial position for the reconstructed superficial MCL. In our patients we did observe mild medial insufficiency of the knee ligaments. Most of the patients ( 12 patients) had a 0 to 1 plus valgus stress test. This fact shows the efficiency of this method for medial side stabilization. A complication of the knee surgery such as knee stiffness which is a common problem in anatomical reconstructions, seen up to $20 \%$ of the time, is rare in our patients. This may be related to smaller incision and less aggressive method of surgery needed in this technique [14]. La Prade explained that if distal attachment of graft be positioned anterior to pes anserinus leads to more failure [22]. The limitation of this method of treatment is the inevitable anterior attachment of the reconstructed ligaments, which theoretically can lead to failure. Having said that, we did not observe any failure using this method.

\section{Conclusion}

This technique is a simple and effective method of MCL reconstruction which can be easily learned. The time of surgery is short, with no fear of longstanding tourniquet time and the incision needed is small compared with more complex techniques of reconstruction. It has lower rate of knee stiffness, with acceptable functional results.

\section{References}

1. Miyasaka K, Daniel D, Stone M, Hirshman P (1991) The incidence of knee ligament injuries in the general population. Am J Knee Surg 4(1): 3-8.

2. Fetto JF, Marshall JL (1978) Medial collateral ligament injuries of the knee: a rationale for treatment. Clin Orthop Relat Res 132: 206-218.

3. Miyamoto RG, Bosco JA, Sherman OH (2009) Treatment of medial collateral ligament injuries. J Am Acad Orthop Surg 17(3): 152-161.

4. Indelicato PA, Hermansdorfer J, Huegel M (1990) Nonoperative management of complete tears of the medial collateral ligament of the knee in intercollegiate football players. Clin Orthop Relat Res 256: 174177.

5. Shelbourne KD, Porter DA (1992) Anterior cruciate ligamentmedial collateral ligament injury: Nonoperative management of medial collateral ligament tears with anterior cruciate ligament reconstruction: A preliminary report. Am J Sports Med 20(3): 283-286.

6. Millett PJ, Pennock AT, Sterett WI, Steadman JR (2004) Early ACL Reconstruction in Combined ACL-MCL Injuries. J Knee Surg 17(2): 9498.

7. Hillard Sembell D, Daniel DM, Stone ML, Dobson BE, Fithian DC (1996) Combined injuries of the anterior cruciate and medial collateral ligaments of the knee. Effect of treatment on stability and function of the joint. J Bone Joint Surg Am 78(2): 169-176.

8. Halinen J, Lindahl J, Hirvensalo E, Santavirta S (2006) Operative and Nonoperative Treatments of Medial Collateral Ligament Rupture With Early Anterior Cruciate Ligament Reconstruction A Prospective Randomized Study. Am J Sports Med 34(7): 1134-1140.

9. Larson RL (1980) Combined instabilities of the knee. Clin Orthop Relat Res 147: 68-75.

10. Robins AJ, Newman AP, Burks RT (1993) Postoperative return of motion in anterior cruciate ligament and medial collateral ligament injuires The effect of medial collateral ligament rupture location. The Am J Sports Med 21(1): 20-25.

11. Azar FM (2006) Evaluation and treatment of chronic medial collateral ligament injuries of the knee. Sports Med Arthrosc 14(2): 84-90.

12. Bosworth DM (1952) Transplantation of the semitendinosus for repair of laceration of medial collateral ligament of the knee. J Bone Joint Surg Am 34(1): 196-202.

13. Kim SJ, Lee DH, Kim TE, Choi NH (2008) Concomitant reconstruction of the medial collateral and posterior oblique ligaments for medial instability of the knee. Bone \& Joint Journal 90(10): 1323-1327.

14. Lind M, Jakobsen BW, Lund B, Hansen MS, Abdallah O (2009) Anatomical reconstruction of the medial collateral ligament and posteromedial corner of the knee in patients with chronic medial collateral ligament instability. Am J Sports Med 37(6): 1116-1122.

15. Borden PS, Kantaras AT, Caborn DN (2002) Medial collateral ligament reconstruction with allograft using a double-bundle technique. Arthroscopy 18(4): E19.

16. Fanelli GC, Tomaszewski DJ (2007) Allograft use in the treatment of the multiple ligament injured knee. Sports Med Arthrosc 15(3): 139-148.

17. Feeley BT, Muller MS, Allen AA, Granchi CC, Pearle AD (2009) Biomechanical comparison of medial collateral ligament reconstructions using computer-assisted navigation. Am J Sports Med 37(6): 1123-1130. 
18. Wijdicks CA, Griffith CJ, Johansen S, Engebretsen L, LaPrade RF (2010) Injuries to the medial collateral ligament and associated medial structures of the knee. J Bone Joint Surg Am 92(5): 1266-1280.

19. Gorin S, Paul DD, Wilkinson EJ (2003) An anterior cruciate ligament and medial collateral ligament tear in a skeletally immature patient: a new technique to augment primary repair of the medial collateral ligament and an allograft reconstruction of the anterior cruciate ligament. Arthroscopy 19(10): e21-e26.

20. Marx RG, Hetsroni I (2012) Surgical technique: medial collateral ligament reconstruction using Achilles allograft for combined knee ligament injury. Clin Orthop Related Res 470(3): 798-805.

21. Creighton RA, Spang JT, Dahners LE (2005) Basic science of ligament healing: medial collateral ligament healing with and without treatment. Sports Medicine and Arthroscopy Review 13(3): 145-150.

22. LaPrade RF, Wijdicks CA (2012) Surgical technique: development of an anatomic medial knee reconstruction. Clin Orthop Relat Res 470(3): 806-814.

23. Coobs BR, Wijdicks CA, Armitage BM, Spiridonov SI, Westerhaus BD, et al. (2010) An in vitro analysis of an anatomical medial knee reconstruction. Am J Sports Med 38(2): 339-347.

24. Van den Bogaerde J, Shin E, Neu C, Marder RA (2011) The superficial medial collateral ligament reconstruction of the knee: effect of altering graft length on knee kinematics and stability. Knee Surgery, Sports Traumatol Arthrosc 19(1): S60-S68.

\section{Your next submission with Juniper Publishers} will reach you the below assets

- Quality Editorial service

- Swift Peer Review

- Reprints availability

- E-prints Service

- Manuscript Podcast for convenient understanding

- Global attainment for your research

- Manuscript accessibility in different formats

( Pdf, E-pub, Full Text, Audio)

- Unceasing customer service

Track the below URL for one-step submission https://juniperpublishers.com/online-submission.php 